\title{
EDITORIAL
}

\section{INSURANCE: SOLIDARITY OF RISKS OR MARKET PLACE?}

The Insurance industry operates on the basis of two different paradigms, to which - depending on the forces exercised by cultural environment and by historical trends - different societies attach different weights.

\section{INSURANCE AS RISK COMMUNITY}

In this view, insurance is generated by the "community of risks". The effect of pooling allows the individual to bear risks, which - if he were left alone - would economically destroy him. In this understanding of insurance, the role of the insurer is limited to that of trustee and administrator. He should receive fair compensation for his administrative tasks but for him to profit from the risk itself would be contradictory to the basic idea.

\section{INSURANCE AS AN ECONOMIC FUNCTION}

This function consists in the creation of contingent money; i.e. money which takes value only if a well defined ("insured") event happens. Imagine a piece of paper on which an event A is marked. The paper's worth is one unit of currency - but "only if " A occurs. Economists call such a piece of paper an "Arrow Certificate". Economically insurance is nothing else than the market of such certificates. On this market the insurer is a powerful player who like everybody else acts according to the principle of profit maximisation.

It is tempting to associate these two paradigms with two different cultural values of society.

The first paradigm may be associated with the values of collectivity and solidarity in mankind: The individual is tied into the net of all other individuals. The prevailing order of society demands from the individual responsibility for the whole society. In compensation society shelters the individual and protects it. The emphasis is on human need. Human rights and obligations are more important than human freedom. The common institutions are the stronghold of society.

Continental European understanding of insurance has-over the last 100 years - been predominantly marked by these cultural values of collective solidarity. Insurance is seen as an organisation of the "risk community". The insurer's role is that of a trustee and the state has the responsibility to watch that the community functions properly. Little faith is placed in the judgement of the individual who needs rather to be protected from irresponsible insurance speculators. The complexity of insurance products and the long term nature of many insurance contracts are typically advocated to justify this protection.

The second paradigm corresponds to the individualistic or liberal values of man. In this view of man it is believed that assuming responsibility for others generally exceeds the limits of human abilities. It is better for mankind as a whole if each 
individual cares for his own and his family's problems. These basic convictions reflect also on the economic order, where responsibility for the well being of the individual is his own. Thus relations between individuals rely on service and return rather than on need and contribution. The common institution is no longer the decisive entity, the market takes its place. On the scale of society the emphasis is more on individual freedom than on duties and rights.

There is no doubt that the EU Commission - with its third generation of insurance guidelines - has clearly chosen a route towards these more individualistic liberal values. Traditionally the Anglosaxon culture has been more centered around them, but it seems evident, that in future decades, these individualistic values will gain importance in Continental Europe as well as possibly-but not necessarily - throughout the whole world.

It is futile to discuss the pros and cons of the two systems of value. As the path into the future has already crystallised we had better ask what it means to us, insurers and actuaries in particular, when - as foreseeable - the insurance world will become much more market oriented.

For today - let me concentrate on one aspect which is particularly important for us actuaries: The role of information. Theoretically there is no doubt and you can read it in any text on economics : the market economy can only function perfectly if all agents participating in the market have complete (this is the word of the economists, not mine) information about the traded goods and services. Delegation of the responsibility, with all its consequences, to the level of the individual makes sense only if this individual has all the information which is needed to assume this responsibility. Taking again the $\mathrm{EU}$ as an illustrative example, it is obvious that - again theoretically - the whole complex of information has been addressed: the guidelines for the harmonization of insurance accounting are aiming at increased transparency.

In practice however there is still a long way to go. How can the individual consumer - in the future - distinguish a serious insurance product from a hazardous gamble?

At the ASTIN Colloquium in Cambridge I have challenged our profession - the actuarial profession - to become active in the area of insurance information and I have given a few examples of how this might be realized:

- Creation of an independent Rating Agency on a truly international level, which classifies insurance carriers according to their solidity.

- Open declaration of methods e.g. those underlying the calculation of claims reserves.

- Mutual peer review of actuarial work even between competing companies.

If the insurance industry of the future puts more emphasis on the market mechanism, then we must also make every effort to ensure that this market is functioning well. To this end customers urgently need more transparent information on insurance products and on the quality of the institutions which create and manage them. Who other than we actuaries might better deliver the yardstick for the necessary measurements?

Let me add a final point. Clearly, in the past and in all cultures, the actuary's role has been to provide a scientific basis for decisions and to inform about facts. In this role he has often been called the "conscience of insurance". Traditionally the 
actuary has exercised this role internally, inside insurance companies, supervising offices and committees. This will no longer suffice. The actuary must also serve the external world, the buyers of insurance and the public: The contributions of the actuarial profession to the market economy will be measured by how much we contribute to its transparency!

Hans BüHLMANN 